\title{
God, Physicalism, and the Totality of Facts
}

\author{
ANDREA CHRISTOFIDOU
}

\begin{abstract}
The paper offers a general critique of physicalism and of one variety of nonphysicalism, arguing that such theses are untenable. By distinguishing between the absolute conception of reality and the causal completeness of physics it shows that the 'explanatory gap' is not merely epistemic but metaphysical. It defends the essential subjectivity and unity of consciousness and its inseparability from a self-conscious autonomous rational and moral being. Casting a favourable light on dualism freed from misconceptions, it suggests that the only plausible way forward in the search for an understanding of both physical and mental reality is a recognition of the mind as a metaphysically distinct entity.
\end{abstract}

If every age has a spirit, physicalism is the spirit of this age, and was for the most part of the twentieth century. ${ }^{1}$ Yet we still do not have a clear conception of what the physical is. Its defenders have at best advanced accounts of what the physical is not, but have provided no positive account. As David Papineau states, the physical can be understood to mean the non-mental and this "is just what we need for philosophical purposes." 2 My main concern is not directly with this general issue, but with examining some of the tenets of physicalism. Physicalist philosophers who do not accept some form of outright eliminativism of the mental are faced with the problem of reconciling the truth of physicalism with what they referred to as mental realism. The issue is whether, given the truth of physicalism, the physical determines the mental along the lines defended by, among others, Jaegwon Kim, who states the thesis thus: "once the

1 Philosophers such as Karl Popper rejected this idea of the spirit of the age precisely because of the possibility of the dangerous consequences that it might have, such as the dismissal of any thesis likely to go against that spirit. An instance of this can be seen in the general acceptance of "the dogmatic rule that dualism is to be avoided at all costs." Daniel Dennett, Consciousness Explained (Boston: Little, Brown \& Co., 1991), 37; his italics.

2 David Papineau, 'The Rise of Physicalism', in Physicalism and its Discontents, Garl Gillett and Barry Loewer (Eds.) (Cambridge: Cambridge University Press, 2001), 3-36, 12. 


\section{Andrea Christofidou}

physical side of our being is completely fixed, our psychological life is also completely fixed."

I shall begin with a brief exposition of a line of argument levied against such a thesis by Tim Crane ${ }^{4}$ not so much with a view to a defence of the thesis (dubbed by Crane supervenience physicalism, henceforth SP), as to demonstrate that the thesis of non-physicalism defended by Crane (and no doubt by other philosophers) is unstable and ultimately untenable. If SP is false, if non-physicalism can be shown to be unstable, and if reductionist and eliminativist versions of physicalism are implausible, the question then arises: what are the implications facing us in our search for an understanding of the nature of the mind?

\section{I}

Crane argues that SP is ultimately false, despite what he sees as its initial appeal: that its guiding assumption is mental realism. His examination of SP reveals an inherent dilemma, the first horn of which threatens physicalism, while the second threatens mental realism. SP cannot sustain either of these claims, so-given its original motivation, the desire to give a naturalistic account of the mental-it collapses. The ins and outs of all this are fully and clearly discussed by Crane, and I shall not repeat them here. Rather, I should like to concentrate on some of the central issues concerning Crane's own thesis, the proper moral of which, he says, seems to be this:

The physical only determines or fixes the mental by means of psychophysical laws. Since a psychophysical law is surely a mental fact, then it is not true to say that the physical facts alone determine the mental facts. But this being said, there would not seem much point in saying that the physical facts plus the non-physical laws determine the mental facts. For this just seems to be another way of putting the unilluminating truth that the totality of facts, including the laws, determine the mental facts. Unilluminating, but at least true: all God has to do to create thought is to create the facts, whatever they may be. ${ }^{5}$

3 Jaegwon Kim, 'Psychophysical Supervenience', Philosophical Studies, 41 (1982), 51-70.

4 Tim Crane, 'All God Has to Do', Analysis, 51 (1991), 235-244.

5 Crane (1991), 243. 


\section{God, Physicalism, and the Totality of Facts}

The central point of his thesis, contrary to SP, is that the physical alone cannot fix the mental; rather, it is the physical facts plus the nonphysical laws that determine the mental. If this is correct, then God creates, along with the physical facts and physical laws, the psychophysical laws; God "has to create laws in which mental properties figure." It is precisely this that constitutes the first horn of the dilemma that threatens SP, for "if there are psychophysical laws, there are mental properties and facts." The core of the thesis "depends on a simple biconditional: there are mental properties if and only if there are psychophysical laws." What is a law? Crane explains that a law tells us what the general features of the world are, and these general features or properties of the world are what make law-statements true. If this is right, the mental properties are precisely what make the psychophysical law-statements true. The claim "is that the existence of mental properties entails the existence of some mental laws whether psychophysical or purely mental."6 If there are no psychophysical laws, "there are no genuine mental properties at all." This generates the second horn of the dilemma that threatens SP, because SP is committed to psychophysical laws but at the same time denies that anything other than the physical is needed in order completely to fix the mental. Consequently, SP denies that it is nomologically possible that there be mental differences without physical differences.

Crane, however, argues that his naturalistic non-physicalistic position is consistent with the nomological possibility that there are two people who share all their physical properties yet differ in their mental properties. This is because it is very likely that many psychophysical laws are not deterministic, so they may very well entail that there be two physical particulars that share their physical properties but differ in their mental properties-as a matter of law. But as a matter of fact it is unlikely that this possibility will be actualised, because the immense physical complexity of anything capable of having a mind will ensure that there will never be two people sharing all their physical properties. This fact, however, should give no comfort to SP.

The conclusion is that $\mathrm{SP}$ is unstable concerning the genuine reality of the mental, and ultimately false, but I shall argue that this form of non-physicalism shares that instability. My discussion examines its commitment to both mental realism and naturalism. As we have seen, a dilemma inherent in SP has been revealed, the first

6 Crane (1991), 239. 
horn of which threatens the truth of physicalism, while the second threatens the truth of mental realism.

\section{II}

The truth of physicalism is assumed, ${ }^{7}$ implicitly or explicitly, by most participants in this debate, including Crane, for despite his insistence that he is a non-physicalist (though not a dualist), he argues that (i) "all empirical particulars either are physical or are composed out of microphysical parts"; he qualifies this commitment by saying that (ii) his non-physicalism "is plausibly a thesis about properties, not particulars: physical particulars can have irreducible nonphysical properties," 8 and that (iii) the physical facts, though necessary, are not sufficient for determining the mental facts.

Before turning to non-physicalism, a more general discussion of physicalism will shed some light on its seductiveness. The discussion will lead to a consideration of the absolute conception of reality or the totality of facts, its conflation with the scientific conception and the causal completeness of physics.

What has given rise to physicalism? Papineau gives a two-pronged response: first, that the thesis of the completeness of physics is a thesis concerning physical causes and physical laws: "All physical effects are determined or have their chances determined by prior physical [causes] according to physical laws." 9 Secondly, that it is such a thesis, together with the suggestion that the thesis has an empirical basis, which has led to the widespread influence and acceptance of physicalism in the philosophy of mind.

Physicalism has not confined itself to the philosophy of mind, but has spread into other areas such as moral philosophy; thus some philosophers argue that even if it is granted that moral terms do purport to describe sui generis moral properties or facts, such descriptions are ultimately false because metaphysically speaking there are no such properties or facts. Moral properties and values, we are told, are not

7 "Many philosophers do not give any arguments for physicalism, but take some such position for granted in all their reasonings." Jennifer Hornsby, 'Physicalism, Events and Part-Whole Relations', in Actions and Events: Perspectives on the Philosophy of Donald Davidson, Ernest LePore and Brian McLaughlin (Eds.) (Oxford: Basil Blackwell, 1985), 444-460, 445.

Tim Crane, 'Reply to Pettit', Analysis, 53 (1994), 224-227, 224.

9 David Papineau, Philosophical Naturalism (Oxford: Blackwell 1993), 16. 


\section{God, Physicalism, and the Totality of Facts}

part of the fabric of the world, and even if there were such properties, the so-called argument from queerness contends that they would be utterly different from anything else in the universe, they would be of a very strange and queer sort. And the conclusion drawn is that it is most likely that there aren't any such radically queer things. The upshot is the attribution of the error theory ${ }^{10}$ to the entire human race; the whole of humanity, throughout its history, purporting to make objective moral judgements, has been systematically in error because such judgements are simply false (or meaningless). Arguments that move from the irreducibility of, say, a property or a particular to its denial appear to be devoid of substance, but it is still useful to ask what their basis is-what is the driving force of physicalism?

Its driving force seems to be the success of science in unravelling some of the mysteries of the physical world. Science's splendid achievements have led a number of philosophers to assume that the fabric of the world is what can ultimately be expressed by empirically and scientifically verifiable statements-what an exact science can describe and explain without remainder as the true arrangements of the ultimate furniture of the universe. From this standpoint, it is a short step to the claim that if there were moral properties, and for that matter distinct minds, they would be of a queer sort in the former case, and mysterious or supernatural in the latter case; in both cases they would be utterly different from anything else in the entire universe, ${ }^{11}$ and therefore suspicious. Anything irreducible to scientific explanations or falling outside the realm of the special sciences is considered to be manifestly unscientific, violating the realm of laws.

But what is the universe, what does it consist in, and have we or can we have exhaustive knowledge of it? The term 'universe' is a unifier of all that is the case, but the physicalists' assumption is that the reference of 'universe', if it is to have an impact on ontology, an impact at the level of particulars, must be whatever can fall within the subject-matter of physics and other special sciences. The entire universe is conceived as an arrangement of microphysical particles and concomitant fields of force, governed by the microphysical laws which in turn govern everything ${ }^{12}$ - they govern the behaviour of

10 J.L. Mackie, Ethics: Inventing Right and Wrong (Middx.: Penguin Books Ltd, 1977), 35.

11 Mackie (1977), 38.

12 Philip Pettit, 'A Definition of Physicalism', Analysis, 53 (1993), $213-223,217$. 
the wholes. The compositionality thesis establishes a hierarchy of different levels of thing, a hierarchy of special sciences (possibly irreducible) with their special laws, and for nonphysicalists there is no reason that psychology should not be one such special science operating in the space of causes and the realm of laws. Given all this, and given the premise that the physical is nonmental, it seems to follow that if the mental is to have any legitimacy it must have arise from certain organisations of matter, or be composed out of the physical, determined or fixed by the physical laws (though for nonphysicalists the physical only determines or fixes the mental by means of psychophysical laws). Objectivity, truth, legitimacy fall on the side of the physicalist and scientific conception of the world.

What follows is a conflation of all that is the case, the absolute conception of reality, with the scientific conception, and in turn a conflation of the physical world with the empirical world: "it isn't crucial that you know exactly what a complete physics would include. Much more important is to know what it won't include" Papineau claims. Responding to the objection that, despite the dominance of physicalism in the philosophy of mind for more than half a century, we still have no clear understanding of what the physical is, he states: "suppose you understand physical as simply meaning nonmental $[\ldots]$. This understanding [...] might seem a lot weaker than most pretheoretical understandings [...but] it is just what we need for philosophical purposes, because it still generates the worthwhile conclusion that the mental must be identical with the non-mental-given, that is, that we are entitled to assume that the non-mental is complete." 13

In support of this assumption, the physicalists draw on a wellknown causal argument: (i) the thesis of no overdetermination, (ii) the premise that any property (mental or physical) that has a physical or non-mental effect is itself physical or nonmental, and (iii), the premise that physics is causally complete. To argue against this argument would be to buy, we are told, "into the Cartesian picture, a picture that no physicalist could tolerate", ${ }^{14}$ or to come up against "[t]he central problem facing any contemporary dualist [...] that twentieth-century science denies any causal powers to unreduced phenomenal properties." 15 Denying, or not tolerating a position,

\footnotetext{
13 Papineau (2001), 12.

14 Jaegwon Kim, Philosophy of Mind (Oxford: Westview Press, 1996), $147-8$.

15 David Papineau, 'A Universe of Zombies?', Times Literary Supplement (21 June 1996).
} 


\section{God, Physicalism, and the Totality of Facts}

however, is not equivalent to proving that it is invalid or false. Nevertheless, once the equivocation between the absolute and the physicalist conceptions is in place, it seems irresistible not to suppose that all particulars and all genuine truths about the particulars must be discernible from the physicalist conception. Consequently, we come to think that we have a metaphysical basis for the scientific conception as a conception of the universe, and hence a metaphysical justification for physicalism in all its varieties.

When, however, in a moment of reflection we step back and disentangle the absolute from the physicalist conception, we no longer have a metaphysical reason for thinking that every particular is principally a physical particular, that mental particulars and moral values are supernatural or of a queer sort. We no longer have compelling reasons to accept that the mental must be identical with, or composed out of the non-mental, or that the physical only determines the mental by means of psychophysical laws. Only if one adheres to some variety of empiricism that urges us, paradoxically on the basis of the metaphysics of physicalism, to abandon metaphysics or "the goal of a first philosophy", ${ }^{16}$ and which labels many metaphysical claims as "pseudo-statement(s) without cognitive content", 17 would one be led to claim that the mind is supernatural. It is one thing to have philosophical respect for science and its exceedingly impressive progress and achievements, it is quite another to think that anything that does not fit within the sciences must be an embarrassment, or supernatural, or mythical. The problem seems to be not with science but with physicalists whose conception neatly represents, as Peter J. King puts it, "the scientism which underlies much opposition to dualism. It is in fact little more than an appeal to authority - though, oddly, to an authority which is essentially mutable and incomplete: contemporary science." 18

16 W.V. Quine, 'Five milestones of empiricism', in his Theories and Things, (Cambridge, Mass: Harvard University Press, 1975), 67-72, 72. Quine takes such abandonment to involve the denial that our knowledge can be "answerable to any supra-scientific tribunal".

17 Rudolf Carnap, 'Empiricism, semantics and ontology', (reprinted) in Philosophy of Mathematics: Selected Readings, P. Benaceraff and H. Putnam (Eds.) (Cambridge: Cambridge University Press, 2nd edn., 1983), 241-257, 250 .

18 Peter J. King, 'One Man's Meat Is Another Man's Person', in Mind and its Place in the World: Non-Reductionist Approaches to the Ontology of Consciousness, Alexander Batthyany and Avshalom Elitzur (Eds.) (Heusenstamm nr Frankfurt: Ontos Verlag, 2006), 61-76, 63. 
A pressing task must be to give as clear an elucidation as possible of the absolute conception of reality on the one hand, and the physicalist scientific conception on the other. Although that task is beyond the scope of this paper, some preliminary discussion is in order.

\section{III}

We can grant that the scientific investigation might be striving towards a Peircean ideal convergence and success for all its practitioners including the special sciences, and its power "would lie in its being explanatory, and in the way in which it would be explanatory." 19 But such convergence and success would be scientific and thus its completability would be in terms of its subject-matter and within its own frame of reference. It would not be the absolute conception of reality or the totality of facts. We are led to believe that the scientific conception is the absolute conception that will provide an explanation of everything that is part of the fabric of the world, but it seems that we are led to all this as a result of an equivocation between 'everything' referring to what is part of the fabric of the world, and 'everything' referring to what is accepted by the causal argument and the scientific conception.

Thomas Nagel ${ }^{20}$ has described the absolute conception of reality as both centreless and featureless, and has argued that the absolute conception would be incomplete. I think that he is right that the absolute conception would be centreless, but wrong that it would be featureless and incomplete. ${ }^{21}$ The absolute conception must, by definition, include everything - it must be a conception of the totality of facts, a complete unified totality. It must include, if it is to be consistent with itself, not only the possibility of scientific convergence but also, along with all other possible sentient and intelligent beings, facts about us and our essential subjectivity, and facts about what is of value in

19 Bernard Williams, Descartes: The Project of Pure Enquiry (The Harvester Press Ltd, 1978), 244. My characterisation of convergence is neutral with regard to the current and widely held view that the unity of science, in the sense of the reducibility to physics of all scientific doctrines, is indefensible. There might be convergence in the sense of contributing to the inventory of what the physical fabric of the world contains.

20 Thomas Nagel, The View from Nowhere (New York: Oxford University Press, 1986).

21 I have discussed these issues in greater detail in my doctoral thesis: The Metaphysics of the Self: Self-identification and Self-ascription (University of London, 1993). 


\section{God, Physicalism, and the Totality of Facts}

itself. Indeed, Nagel does concede that the absolute conception might include all points of view and subjective experiences; but then, it can be neither featureless, nor incomplete. What would be featureless and incomplete would be the scientific conception, since whatever the fundamental laws of physics and the laws of special sciences would be on the basis of which the ideal convergence might be achievable, it would still not be the absolute conception. The scientific conception has no room for colours or sounds as we understand them (I say 'understand' rather than 'perceive' for it does not follow that secondary qualities do not exist unperceived), even if it (and physicalism alike) can give a reductive account of such qualities; it has no room for demonstratives, indexicals, tensed or other token reflexive expressions; it cannot accommodate us as autonomous rational and moral beings, and by that very fact renders itself featureless or etiolated and incomplete.

But in so far as the scientific conception cannot include us in its inventory as autonomous rational and moral beings, it does not follow that it can obliterate us from the fabric of the world. That what is part of the fabric of the world is more than just what is investigated, described or possibly explained by the scientific conception seems to be not only true, but nontrivially true. What is 'more than' cannot, without reflection, be pejoratively branded unscientific or an illusion. A thesis or a theory that is non-scientific can be robust, rigorous, and analytical, and have the power to elucidate in a systematic, clear, and cogent way what can be part of the fabric of the world without being subject to scientific descriptions and investigations. If it were the case that our conception of ourselves as autonomous rational and moral beings is an illusion, that our conception of mental phenomena constitutes a radically false theory, as physicalists too often and too readily claim; if, as nonphysicalists claim, "there are no subjective facts about anything", and if "perspectival facts are false projections of first-person present-tense knowledge", ${ }^{22}$ one asks (with David Ross): if reason has made such egregious errors about itself, what is it that reassures these philosophers that reason can be trusted in its power to know anything at all? ${ }^{23}$ It is rash to think that what is real must always be mind-independent or be understood in an independent way, or be modelled on our scientific theories and investigations, since the latter can deal with only one part of what we

22 D.H. Mellor, 'Nothing Like Experience', Proceedings of the Aristotelian Society, vol.XCIII (1993), 1-16, 2.

${ }_{23}$ W.D. Ross, The Right and the Good (Oxford: Clarendon Press, 1930), 82. 
as rational enquirers are striving for. In searching after truth, the rational enquirer is trying to establish the nature and possibility not only of scientific knowledge, but of knowledge in general. And for the classical philosophers, and for philosophers such as Descartes, Spinoza, and Kant, the rational enquirer is also aspiring to and striving towards the perfection that pertains to its kind.

Indeed, the reasons that led Descartes to draw the distinction between the essential natures of mind and corporeality show the limits of any scientific investigation as to the nature of what there $i s .{ }^{24}$ Such reasons were based neither on doubt, ignorance, or imaginability, nor on intuitions dependent on the first-person point of view, but on a painstaking examination and as clear and distinct a conception of the facts as possible. Even if he had expected the results of his enquiry to have been otherwise, in light of the advent of modern science at the time he was writing, as a searcher after truth Descartes was not seduced by that fervour and excitement but followed the arguments where they led him.

Our understanding of what the absolute conception would be, admittedly, leads us to something odd: a paradox - the paradox of subjectivity, as I should call it. On the one hand, the absolute conception must be a conception of completeness, of the totality of facts, it must include me as an irreducible rational and moral being, but on the other, it cannot accord me any special centrality-it cannot accord any centrality to the self's special position and point of view from which it aspires to apprehend the universe, and it cannot accord any special status to what is of value (for anyone who can comprehend it). The paradox of subjectivity, I believe, is unresolvable because the absolute conception is a conception of reality sub specie aeternitatis, one that is complete, eternal, and centrelessone that it makes no sense to think can be attained.

Nagel has argued that any centreless description of the world, even if it included all points of view and subjective experiences, would lack an important fact: the fact that I am a particular person in it. But what would an absolute centreless description be, and how would we know that we have attained it, since the possibility of reality being more than we can grasp will always be open? It would not be, as we have

24 René Descartes, The Philosophical Writings of Descartes. John Cottingham, Robert Stoothoff, Dugald Murdoch (transls.) (Cambridge: Cambridge University Press, 1984). Abbreviated: Descartes, CSM, 1 and CSM, 2. The abbreviation for The Correspondence, John Cottingham, Robert Stoothoff, Dugald Murdoch, Anthony Kenny (transls. 1991) is: Descartes, CSMK, 3. 
seen, a scientific description, nor would it be an objective description which attempts to give an account of the world from no parochial or distorted point of view. The objective description would be an expanded conception, one that would at least show, along with all other possible explanations, the possibility of finding a place in the world of the reality and determinacy of the mind and its essential properties, of values, of secondary qualities; one that should be able to overcome custom and habit, preconceived opinions and prejudices, dogmatism, relativism and parochialism in our view of reality. Our ability to overcome such views of reality necessarily requires our having a conception of reality "which contains a theory of error: which can explain the existence of rival views, and of itself" 25 or, as I should put it, which contains the methodic doubt or scrutiny as its guiding and invaluable injunction for any rational enquiry.

If these considerations, albeit summarily sketched here, are cogent, then it is not so much that the absolute conception would lack any facts (for if it did it would not be absolute, complete, or the totality of facts), but given that it must be centreless, it cannot accord me as an autonomous rational and moral being the self-reflective thought that I am a particular person in it, although it must include such a fact. It cannot accord me this thought because such a thought can be conceived and understood only from a conception sub specie durationis, not sub specie aeternitatis. ${ }^{26}$ The absolute conception cannot accord me any special centrality: that is the irresolvable paradox of subjectivity. It is futile to try and forge such a special centrality in that all-encompassing centreless conception, and we should fool ourselves if we thought that in striving for the attainment of any objective truths that can have absolute status of what there is, we should thereby arrive at every objective truth. As Descartes argues, this is the true meaning of a finite understanding. The attainability of truths that have absolute status, or of absolute knowledge of how things are, is not the same as the attainability of knowledge of the absolute conception of reality, of the totality of facts.

That we shall be unable to attain the absolute conception of reality, something that Nagel rightly admits at the beginning of his book

25 Williams (1978), 301.

26 I must make clear that the truth of any clear and distinct propositions remains absolute and does not fall short of any determinate facts. As Wiggins puts it: "Absoluteness is not a modality of truth. It is a feature of sense, one might say, not reference." David Wiggins, Needs, Values, Truth (2nd edn.; Basil Blackwell Ltd, 1987), 343, fn.24. 
The View from Nowhere, should not frustrate our enquiries into objectivity and truth, nor should it lead us to jettison such a conception; otherwise the threat of scepticism arises, and there is a world of difference between a conception that strives for the possibility of truth and objectivity and one of radical scepticism that attempts to rule it out. The absolute conception of reality is the regulative principle, the aspirational and necessary presupposition of the possibility of knowledge in general. It is a reminder that reality is potentially larger than we can or can hope to grasp, but it also sets us off in the right direction. As Spinoza would argue, if the absolute conception of reality were attainable by us, we would be Deus sive Natura (God or Nature).

\section{IV}

With this background in place, let us turn to the question of how a physical particular can have nonphysical properties. Physicalists (except those who adhere to the most implausible forms of physicalism) generally appeal to the idea of emergent properties as a possible explanation. It is argued that the thesis of emergent properties and the thesis of nonreductive physicalism are metaphysically identical, though differ in their respective epistemic approaches. ${ }^{27}$ Although at the fundamental level there are no mental properties ( pace panpsychism), at the higher level of immense physical complexity a physical particular can have such properties irreducibly.

Despite the coherence and cogency of the thesis of emergent properties in the sciences, it seems to face a dilemma when applied to mental reality: either the emergent properties must be metaphysically distinct from the physical, or emergentism cannot support genuine mental realism. The first horn of the dilemma implies dualism (though not unproblematically as we shall see below), but nonreductive physicalists and nonphysicalists reject dualism. The second horn implies nonreduction at a higher level of complexity, but there are many reasons to be sceptical about its applicability to the mental. We can maintain, for example, that liquidity, fire, gravity, or even life can be shown to have arisen from physical complexity and are governed by physical, or physico-chemical, or physico-biological laws, since they are not distinct in kind from the complex microphysical configurations that have given rise to them: they are simply at a

27 Tim Crane, 'The Significance of Emergence', in Physicalism and its Discontents, Garl Gillett and Barry Loewer (Eds.) (Cambridge: Cambridge University Press, 2001), 207-224. 


\section{God, Physicalism, and the Totality of Facts}

higher level of complexity. Establishing a hierarchy of different levels of thing, however complex, is not equivalent to establishing different kinds of thing. The crux of the debate must be to show how it follows that the mental (or consciousness which is in fact what is at the heart of the debate) is also not metaphysically distinct. If it is not, how can it be really mental? If it is, how could it have arisen from the physical?28

\section{V}

It is the seriousness of these problems that can be said to give impetus to the thesis of naturalism and motivates the appeal to psychophysical laws, and in turn to a defence of mental causation. As Crane argues, in circumstances in which physical and mental causes are involved then "in any plausible sense in which physical causes suffice for their effects, mental causes can do so too", adding that it does not mean "that there are 'gaps' in the chain of physical causation which beliefs and desires must 'fill' [...but that not] only physical causes are sufficient causes of physical effects." 29 Unlike SP and other orthodox varieties of physicalism, nonphysicalism rejects the causal completeness of physics and the no-overdetermination thesis, and argues for a position "according to which physical effects can have many kinds of cause, none of which have the features Descartes attributed to the mind, and not all of which are physical." 30 Crane does not explain what the features are from which he recoils (but see §VIII below). The position just described, he says, amounts to an innocuous claim, "and is not in conflict with any laws of physics" or with any "methodological principles" which underlie "mechanisms for phenomena." His non-physicalism avoids "guilt by association" because it separates the causal completeness of physics principle from such methodological principles and rejects it.

This form of non-physicalism seems prima facie to be an advancement on the various other forms of physicalism. In particular, it

28 The problem of consciousness, or the reality of the mental, cannot be conflated with the question of living organisms and with what is considered by modern science to have been successfully demonstrated, namely, the breakdown of a categorial distinction or dichotomy between inanimate things and living organisms, the latter, it is argued, have been shown to have a biophysical explanation. Not everything that is alive is conscious, or has a mind, or is capable of thought.

29 Tim Crane, 'Mental Causation', Proceedings of the Aristotelian Society, Suppl. vol.LXIX (1995), 211-236, 230-231.

30 Crane (1995), 230. 
seems to offer a way of looking at how both physical and mental causation have a rôle in bringing about an effect, and how our conception of the world can accommodate the mental. It is an attempt to give mental causation respectability and acceptability (albeit within physicalism), to place the empirical psychology of the mental along with and among the ontologically monistic special sciences, and to align the mental with all other causally and externally characterisable properties. Crane asks, with D.H. Mellor, why "thinking is not a physically respectable property", and what it is that "prevents the empirical psychology of thought [...] adding in its own terms, as physics does, to our inventory of what there is." 31 It is supposed that something about the mental prevents psychology from attaining the ontological authority of physics and chemistry. Even if there are many answers that can be given, none can justify "the prima facie exclusion of psychology from the realm of the physical which is needed to make physicalism a non-vacuous doctrine about the mind." 32

But there are reasons to think that such a thesis is not much of an advance- that it suffers from a number of difficulties that beset any variety of physicalism. First, it is not clear why a genuine mental realist should worry about the vacuity of physicalism as a doctrine of the mind. Secondly, it is not clear whether it does find a place for the mind in the world that differs significantly from physicalism. Crane's defence of mental causation captures both the physicalists' and nonphysicalists' aversion to the possibility of minds being essentially distinct: "it seems an empty terminological decision to call [his] resulting position 'physicalism'-except perhaps to put on the record one's differences with Descartes." 33 Thirdly, and more seriously, on reflection it seems less and less plausible that mental causation can give us an account or an understanding of the essential nature of the mental.

The problem of the nature of the mental is not only concerned with mental causality, nor with the subjective/objective distinction (however variously that distinction has been conceived), nor with the first-person/third-person ascriptions of mental states, since they can be ascribed both from the first- and third- person points of view and are capable of being understood and referred to using our objective mental terms (if Frege and Wittgenstein are right

31 Tim Crane and D.H. Mellor, 'There is No Question of Physicalism', Mind, vol.99 (1990), 185-206, 186.

32 Crane and Mellor (1990), 187.

33 Crane (1995), 235. 


\section{God, Physicalism, and the Totality of Facts}

about the publicity and objectivity of language), without insisting that they can be grasped either sub specie aeternitatis ${ }^{34}$ or physicalistically. Physical terms are objective, but the converse does not follow, nor is third-person ascription equivalent to physical ascription.

The problem of the nature of the mental is a problem of metaphysics. The metaphysical Rubicon has not yet been crossed, and even if we accept that we do not yet have the concepts that might enable us to make the problem more perspicuous, it is unclear whether it can be crossed if we are genuine mental realists. This is another way of saying that the explanatory gap is not simply epistemological since what makes the mind noncomparable with and disanalogous to any examples drawn from science or the special sciences, is precisely its essential connection to a subject. It is not a contingent truth that there is an essential connection between the mind or consciousness and a conscious being, which would imply separability. The problem of the essentially subjective nature of the mind is not and cannot be out there to be investigated independently of $u s$-we are right in it, as it were. Nor is it any clearer how we can arrive at the essential nature of mental reality by arguing that the mental is causally efficacious, operating in the space of causes and the realm of laws (assuming that we have a clear understanding of the nature of causality).

The mind and its properties stand in a special and essential relation to a subject of experience, a subject that is a necessary presupposition for any conscious state. To ignore or sever that relation, or to conduct the debate purely on the basis of mental causation; or to insist that such a thesis is trivial, or uninteresting; or to think that the problem is traceable to the difference between the sense and reference of our terms, would be to misunderstand and to lose sight of the subject-matter of one's enquiry. The nearest nonphysicalism seems to come to an acknowledgement of the subject is from the external causal standpoint, the standpoint of a spectator: ${ }^{35}$ "the particular

34 See my 'First Person: The Demand for Identification-free Self-reference' Fournal of Philosophy, XCII:4 (1995), 223-234.

35 My use of 'external' here is neutral with regard to the internalist/ externalist debate regarding either semantics or the individuation of mental content in terms of truth-conditions. With regard to the latter debate, Descartes argues that clear and distinct propositions are true, they correspond to the nature of things and are neither dependent on, nor individuated or constituted by some internal sensa (CSMK, 3, Letter to Mersenne, 16 October 1639, AT II 597). That the mind is world-involving can be perfectly compatible with Descartes' dualist thesis. 
which has [for instance] the property pain is the very same thing as the particular which has the brain property. That is: me." 36 The property pain, Crane says, is distinct from the brain property.

But in what sense is it distinct? Is it really or metaphysically distinct, which implies dualism? Conceptually distinct, which implies the denial of mental reality? Modally distinct, which implies metaphysical identity? Or numerically or even nomologically distinct, which implies compatibility with metaphysical identity? If numerical or nomological distinctness does not imply such compatibility, then we are back to real or metaphysical distinctness. None of these possible ways of understanding what is meant by 'distinct' is compatible with the tenets of the nonphysicalist's mental realism. Physicalism claims that the physical is non-mental; non-physicalism claims that the mental is non-physical. Without a clear account of the nature of the mental and what is meant by 'distinct', non-physicalism remains unconvincing and incapable of sustaining the genuine reality of the mind and its properties.

\section{VI}

If one is a realist about the nature of what there $i s$, it is the nature or necessity of things that constrains one's thinking, or one's clear and distinct conception, not the reverse. ${ }^{37}$ Clear and distinct conceptions, however, are not just constrained (or caused, as it were) by the nature of things, but also disclose it. The direction of reasoning based on clear and distinct conception is not from our usage of names to the nonidentifiability of the mind with either a property or a physical particular, but vice versa. It is the essential nature of the mind itself that determines the correct signification of the names we use. If it were the usage of names that determined the nature of things, there would be no point in saying that "it is reasonable for us to leave until later the examination of whether these names signify different things or one and the same thing". ${ }^{38}$ The essential nature of the mind

36 Crane (1995), 221.

37 Descartes, CSM, 2: Fifth Meditation (AT VII 66-67).

38 Descartes, CSM, 2: Third Set of Objections and Replies (AT VII 176). The thesis defended here can be perfectly compatible with the idea that there is an interplay between our sortal concepts and the carving up of the world, since the applicability of such concepts is not arbitrary but guided by the nature of things; it is in no way up to us what to count as the essential nature of things, or persistence through time, and so on. See David Wiggins, 


\section{God, Physicalism, and the Totality of Facts}

(indeed, the essential nature of things in general) is the source, not a consequence of the signification and usage of our terms, and constrains us into thinking that there is something fundamentally distinct about it. This does not entail that (human) minds exist separately from bodies; it only entails the logical possibility of their separation.

Stephen Yablo, among many others, thinks that (i) Descartes' dualism entails that mind and body are "metaphysically separate". 39 This is unclear: if it means that they are metaphysically distinct then the claim is true; but if it means that they exist separately, the claim is false, and is based on serious misunderstandings. ${ }^{40}$ Dualism between mind and body is a metaphysical thesis concerned with a real distinction between their essential natures, not their actual separation. ${ }^{41}$ Yablo continues by claiming that (ii) Cartesian metaphysics "breeds epiphenomenalism: the theory that our mental lives exercise no causal influence whatever over the progress of physical events." 42 It is not clear why Cartesian metaphysics would breed such a thesis unless one assumes from the start the truth of physicalism. The mind is not a ghostly entity entrapped in the physical tomb: "I am not merely present in my body as a sailor is present in a ship, but [...] I am very closely joined, and [...] intermingled with it so, that I and the body form a unit" (Sixth Meditation; CSM 2: AT VII 81). If this were not so, Descartes continues, I should simply "have an explicit understanding of the fact" when, for example, the body is hurt and I would feel no pain. His description captures the general position to which current theses are committed: they purport to have or be striving to attain an explicit understanding of the facts, but inevitably remain unable to account for subjectivity and consciousness. The connection between mind and body is reciprocal-a bidirectional causal relation. Indeed, one of the arguments

'On Singling Out an Object Determinately' in Subject, Thought, and Context, Philip Pettit \& John McDowell (Eds.) (Oxford: Clarendon Press, 1986), 169-180; see especially 170 .

39 Stephen Yablo, 'Mental Causation', The Philosophical Review, vol.101, 2 (1992), 245-280, 245.

40 As I have discussed the various misunderstandings and confusions concerning Descartes' dualism (including the so-called argument from doubt which is in fact not Descartes's own argument), I shall not consider them here. See my 'Descartes' Dualism: Correcting Some Misconceptions', The Fournal of the History of Philosophy, XXXIX (2001), 215-238.

Descartes, CSM, 2: Sixth Meditation, AT VII 78.

42 Yablo (1992), 245. 
in the Fourth Meditation is that reason is not limited to its theoretical employment but has direct applicability to activity and conduct, manifested in the correct use of the will-what can be referred to as practical reason or the rational will. ${ }^{43}$

Descartes's conception of ourselves as persons is not as disembodied minds or egos, but as embodied beings-a person is a substantial union of mind and body. He explicitly objected to Regius who claimed "that a human being is an ens per accidens [and not] an ens per se" (and not essentially a unity), ${ }^{44}$ and in a number of places he argues that the union of mind and body is a primitive and unanalysable notion. ${ }^{45}$ If there is a problem with mind/body interaction, it is not one that breeds epiphenomenalism, as we shall see below.

\section{VII}

There is a two-fold response that the non-physicalist can offer. First, that the question "of whether there is 'mental substance' as well as 'physical substance' is an irrelevant one", ${ }^{46}$ and secondly, that "there is no divide between the mental and the non-mental sufficient even to set physicalism up as a serious question" 47 - there is no question of physicalism.

The question of whether there are mental as well as physical substances may be ignored if one's project assumes as a basic premise that all particulars are physical or composed out of microphysical parts, but it can hardly be irrelevant to an enquiry of what there is. Even accepting a theory of properties which states that "being a property just is being a constituent of a law" 48 does not explain why we must accept that mental properties are properties of a physical and not a mental particular (substantially united and causally interacting with a physical particular).

43 I discuss the relation between autonomy, truth, and goodness in 'Freedom, Truth, and Goodness', forthcoming.

44 Descartes, CSMK, 3: Letter to Regius, December 1641, AT III 460.

45 Descartes, CSMK, 3: Letters to Princess Elizabeth, 21 May 1643, AT III 664 ff., and 26 June 1643, AT III 691 ff.; Letter to Arnauld, 29 July 1648, AT V 222; Conversations with Burman, AT V 163 (John Cottingham, [ed.] Descartes' Conversations with Burman (Oxford: Clarendon Press, 1976)).

46 Crane and Mellor (1990), 186.

47 Crane and Mellor (1990), 206.

48 Crane (1991), 241. 


\section{God, Physicalism, and the Totality of Facts}

As to the claim that there is no divide between the mental and the non-mental, one way of understanding it is to think of the mind as a natural phenomenon existing in its own right, not the product of the physical, chemical, or biological. Non-physicalism's ontologically monistic commitment to all particulars being physical, however, rules out the existence of the mind in its own right. ${ }^{49}$ And despite its insistence on the existence of psychophysical laws, the mental is a property and thus it is not clear that it can be instantiated in its own right; rather, it is the physical facts plus the non-physical laws that determine the mental facts.

Moreover, to say that the mental is a natural phenomenon does not explain what its nature is. The naturalness of the mind cannot be set against dualism, since there is nothing supernatural or non-natural in a dualist's conception of the mind-there are no supposed supernatural sources of information about the nature of the mind. There is still a question of physicalism since Cartesian minds are in the empirical world substantially united with bodies, and yet they are not composed of anything physical. As Crane admits: "Mellor and I exaggerated when we said that there is no question of physicalism whatsoever: there is the question of whether this sort of dualism is true." 50 There is no doubt that this sort of dualism has been rejected, dismissed, denied, caricatured, scorned, but it has not been refuted.

Spinoza's ontologically monistic philosophy cannot be appealed to, because it is of a very different kind from contemporary conceptions of monism. The two infinite attributes of God or Nature which are accessible to the human mind, thought and extension, are incommensurable, irreducible, and metaphysically distinct (though, together with an infinity of attributes of the infinite substance, they presuppose a unity), and each "must be conceived through itself." (Spinoza, 1985, I P10). There is no room in Spinoza's ontological monism for the view that the totality of facts, including the laws, can determine the mental facts. Moreover, one of the most problematic issues in Spinoza's metaphysics is: what it is for one and the same entity to have two metaphysically distinct attributes, each expressing a true and immutable essence. He was fully aware of these difficulties, and was led to draw a number of distinctions in his attempt to give a satisfactory account. One such distinction, relevant to our present concerns, comes out of his denial that the one infinite substance (God or Nature) is to be identified with corporeality or corporeal matter. See Spinoza: Complete Works, Samuel Shirley, (trans.) and Michael L. Morgan (Eds.) (Indianapolis: Hackett Publishing Company, 2002), Letter 73, 942; L332= G iv 307/ $11-14$.

50 Crane (1994), 224. 
The non-physicalist might not be unduly disturbed, since he takes it that "part of what naturalism about the mind means is that mental properties belong to the causal order: they participate in causal interactions." As Crane says "on the most popular current naturalist theory of the mind-Functionalism-mental properties are constituted by their roles in the mind's causal architecture." 51 If naturalism is right "there are no mental properties without some psychophysical laws". Crane does not discuss in any detail what 'constituted by' means, though he argues that "the orthodox version of physicalism is now the constitution theory: the theory that mental properties are constituted by physical properties." 52 Given the rejection of physicalism, at least at the level of properties, the suggestion seems to be that naturalism is committed to the thesis that if mental propertiesin so far as they are instantiated-are not constituted by physical properties, they must be constituted (characterised, defined) by their causal rôles. But if this is correct, it is difficult to see how Crane's mental realism might differ substantially from functionalism. Functionalism, in any of its varieties, might tell us something about the functional rôles of a functionally characterised system of causal networks, but it can tell us nothing about the nature of the mind, the nature of both phenomenology and intentionality of mental states, even if it could tell us how they might figure in the causal nexus. The essential nature of things or properties can entail the rôles they can play, whereas such rôles can neither entail nor constitute the nature of things or properties. ${ }^{53}$

In particular, in defending non-physicalism and rejecting dualism, it is unilluminating to say that mental properties participate in causal interactions because dualism, in all but its oddest forms, argues for causal interactions between mind and body. Equally, it is unclear how the theses of causal interaction or of psychophysical causation can be used as an argument against dualism, for they can be used to show that, if there are any explanatory problems with the dualist's mind/body interaction, there must also be problems for any defender of mental realism, and consequently of mental/physical interaction.

Crane, however, states that he can give a non-physicalist description of mental/physical interactions: they are just more non-physical

51 Crane (1991), 241.

52 Crane (1995), 220.

53 This is along the lines of the positions defended by Saul Kripke, Naming and Necessity (Harvard: Harvard University Press, 1980), and Thomas Nagel, 'Conceiving the Impossible and the Mind-Body Problem', Philosophy, 73 (1998), 337-352. 


\section{God, Physicalism, and the Totality of Facts}

laws, "there are physical properties, and irreducible mental properties, and they are linked by (non-physical) psychophysical laws." 54 Descartes too offered not just one but a number of descriptions of mind/body causal interaction. But what he thought was a problem (with which he was concerned not only in his work on metaphysics but also in his work on the principles of physics, as we can see, for example, from the reference he makes to it in his formulation of the third law of motion ${ }^{55}$ ), and what was perceived as such by his contemporaries and by philosophers over the centuries, was the problem of explanation, not of description. No one has yet managed to provide an explanation of what is considered to be an intractable problem: mind/body causal interaction. In fact, given that we seem to have no clear understanding of the nature of causality, ${ }^{56}$ the problem of causal interaction can be generalised to the effect that, if dualism has difficulty explaining mind/body interaction, there is at least as much difficulty and mystery in explaining physical/physical causal interaction, not only for physicalists but for all concerned.

\section{VIII}

Let us now turn to the more general question regarding the mind's architecture. What exactly is it? Indeed, what is the mind, given that nonphysicalism rejects dualism? We have not been given any clear account, except perhaps to say that its architecture is causal and law-like. Reflection on the nature of the mind suggests that it is not simply causal, but far richer and more profound. It presupposes, above all, a conscious subject-however rudimentary that might be. In the case of self-conscious subjects such as us, the architecture of the mind presupposes a rich variety of objective categories and principles. ${ }^{57}$ It consists of powers of discernment and discursive thought, of discretion, discrimination, and judgement; of imagination and

54 Crane (1994), 227.

55 Descartes, CSM, 1: Principles, pt.II, \$40, AT VIII (65).

56 We must be careful not to equate what the nature of causality is with any evidence that we may have for claiming that there are causes or causal interactions. That things causally interact according to causal laws is not a substantive account of what causality is, or indeed, of what it is for something to have causal powers.

The defence of such principles and of what follows here, should give no comfort to a Davidsonian thesis of the mental. Davidson's insight into the irreducibility and normativity of rationality is marred by his monism. $\mathrm{He}$ is wedded to physicalism and thus the most important and insightful 
creativity capable of transcending the ordinary and the mundane; of affection, of sensitivity to and appreciation of the salient; powers of evaluation that presuppose a conception of goodness, of right and wrong, of obligation and responsibility. A human being has the ability in virtue of being self-conscious to stand back and reflect both on itself, on its thoughts, experiences, actions, and on the world at large. It is by virtue of self-consciousness that a subject is accountable for itself and its actions, and through the power of selfreflection the subject is capable of becoming a self-legislating or autonomous being, of aspiring to the universal, to "the true and the good", as Descartes argues in the Fourth Meditation (CSM 2: AT VII 58). There are, undoubtedly, large and complex issues that surround each of the above 'features' of the self-conscious mind, and which deserve serious consideration, but this is beyond the scope of this paper. ${ }^{58}$ What matters for present purposes is that if these are "the features Descartes attributed to the mind" from which philosophers recoil and which lead them to oppose and reject dualism, then it seems inescapable where one's commitment ought to be. They cannot somehow be neglected or render redundant, if one's enquiry is an enquiry into the nature and reality of the self-conscious mind.

If there is experience, perception, thought, even if there is deception or distortion as a result of the wiles of an evil demon, there must be a subject, a perceiver, an experiencer, a thinker. This is the transcendental argument that we find in the Second Meditation. As Descartes clearly saw (and Kant took over), the self and the unity of (consciousness or) self-consciousness can be established neither by empirical observation or investigation of causal connections between, or empirical associations of various mental states or ideas (since they presuppose a unity and cannot constitute it), nor by introspective inspection. ${ }^{59}$ In fact Descartes rejects introspection, or what he calls inner sense, since it can be as liable to error as the external senses (Sixth Meditation; CSM 2: AT VII 76-7). (Reason is the universal and best arbiter for Descartes, not the senses or introspection; hence only clear and distinct conceptions which correspond to or are

part of his thesis turns out to be precarious, since, he states, there is no such thing as the mind, only linguistic mental terms and descriptions.

58 I discuss these issues in my book: Reason, Reality, and Freedom: A New Light on Descartes' Metaphysics, in progress.

59 The issues that surround the topic of the unity of consciousness require another paper and cannot be dealt with here, but it seems to me that Descartes's and Kant's insight are worthy of exploration. 


\section{God, Physicalism, and the Totality of Facts}

directly responsive to the nature of things are indubitable; his notion of conceivability-not imaginability-is not dependent "on the relation between first and third person reference" and thus avoids what Nagel, among many, calls "particularly treacherous terrain." ${ }^{0}$ ) It remains the case that the perceivable and the intelligible cannot become the object of perception or of knowledge and understanding without a subject, any more than the phenomenal and the intentional can be so without a conscious subject. ${ }^{61}$

The unity of self-consciousness is not only a necessary presupposition of, the basic ground for, our explorations concerning our perceptual, emotional, bodily experiences, and so on; it is the fundamental and indispensable condition on the basis of which two thoughts can be connected and an inference drawn. In fact our entire system of thought and logical reasoning would collapse without the subject and the unity of self-consciousness, as is so clearly expressed by Bernard Williams:

"(T1) It is thought: $P$ (T2) It is thought: $Q$

Will it follow that the following is true?

(T3) It is thought: $P$ and $Q$ ”

Without the subject "we must surely grant that T3 cannot follow: a distinct thought-content is involved in T3 and there is nothing in the occurrence of [...] $\mathrm{T} 1$ and $\mathrm{T} 2$ to determine that that thought ever occurred at all. The thoughts T1 and T2 could be [...] 'separate'", 62 could be distinct existences, as Hume would say, without any necessary or inferential connection between them. The same applies, mutatis mutandis, for any putative logically contradictory thoughts. Any attempts to maintain the impersonal formulations but somehow relativise such thoughts to here and now would not in fact help because both here and now are parasitic on the $I$. This does not entail that the subject's conception is self-contained, as has often been claimed, damagingly aligning it with the Empiricist philosophical picture of the introspective and perceptual model of awareness, and unjustifiably branding it Cartesian. Even as early as

$60 \quad$ Nagel (1998), 346.

61 All these are the necessary requirements, it seems to me, that Hume recognised and had the intellectual honesty openly to admit and lament in the 'Appendix' to the Treatise that his account of personal identity failed to provide. The seriousness of the problem recognised by Hume was that without the I or the self, the rest of his enquiry, especially his account of causality which provided a bedrock for his enquire, simply collapsed.

62 Williams (1978), 96-97. 
the Second Meditation, there is nothing in the meditator's conception of himself and of the objective world that does not commit the subject to the intelligibility of an objective and shareable conceptual repertoire; there is nothing that does not conform to Gareth Evans's requirement: just as one's first-person thoughts require the intelligibility of a link with one's conception of an objective world, so one's objective conception of the world requires the intelligibility of a link with one's first-person conception. ${ }^{63}$ Whatever the actual truth of the matter, the intelligibility or objective possibility of such links are part of the meditator's clear and distinct conception.

Truth, validity, autonomy, goodness, are normative notions not causal; logical principles and metaphysical categories are also not causal; how the normative and the causal fit together is certainly one of the main difficulties that needs to be addressed, not bypassed or neglected. To accept or reject, to pursue or avoid, to affirm or deny, to assent to or withhold assent from a proposition, an argument, a position, a thesis, demands that there be good reasons for doing so, as Descartes recognised right at the start of his enquiry. We cannot rest content with the idea that our capacity to reason on the basis of principles and standards, on having good reasons, has only to do with our causal efficacy and biological dispositions, however necessary these may be, since they seem not to add anything that would help to explain either the objective validity and authority of those principles, or what it is to think, or to be conscious-if anything, the direction is the other way. To cash out the architecture of the mind in terms of psychophysical laws, causal rôles, biological dispositions, is in effect not to naturalise the mind but to lose it, and to lose with it the formation of a whole or complete thought or judgement and, consequently, of any meaningful discourse. The requirement of the necessary unity of self-consciousness, as Kant argues, is an objective condition or principle of all knowledge: it is "the highest principle in the whole sphere of human knowledge." 64

\section{IX}

As a last attempt, it might be argued that it is still open to a defender of non-physicalism to retort that naturalism is broader

63 Gareth Evans, The Varieties of Reference (Oxford: Oxford University Press, 1982), 212.

64 Immanuel Kant, Critique of Pure Reason (trans. by Norman Kemp Smith; The Macmillan Press Ltd., 1980), B135; see also B140-2. 


\section{God, Physicalism, and the Totality of Facts}

than the account offered thus far: it can be set against the idea of the immortality of the mind. But such a response cannot be used as an argument against Descartes's dualism since his conception of the mind is also naturalistic. It is evident that in the Meditations he set out to demonstrate no more than the real distinction between mind and body-not the immortality of the mind. ${ }^{65}$ In his reply to Mersenne he concedes that when the body perishes it is possible that the mind "comes to an end simultaneously with the end of the body's life."66 As it happens, most Western theists have been dualists of one sort or another (generally not Cartesian dualists, in fact), but it certainly does not follow that all dualists are theists.

Furthermore, naturalism cannot be set against dualism on the basis that naturalism denies that our cognitive powers are supernatural. Contrary to the views of some of the leading thinkers of his time, ${ }^{67}$ Descartes is concerned with the natural light of reason (not with the light of grace, as John Cottingham suggests, ${ }^{68}$ or with supernatural illumination), and explicitly denies a divine and hence supernatural model of cognition for our own cognitive powers, since divine cognition is inscrutable. It is quite unfair to Descartes to present him as a supernaturalist about reason or the mind, even though he finds that there can be

65 Given the climate at the time, and having been made aware by Mersenne of the literature that was circulating in Paris, and of the decree of the Fifth Lateran Council of 1513, Descartes found the need to say in the Synopsis, that although further arguments were required for the conclusion that the soul is immortal (since this could not be deduced from the argument for dualism), the arguments he had offered were "enough to give mortals the hope of an after-life" (AT VII 14). It may "have been the currency of the debate about the soul's immortality which caused Mersenne to add [those] words to the title of the first, Parisian, edition [...which] shows how Descartes's work could be reduced against the wishes of the author to the terms of a current debate, and its novelty and precision misrepresented." 'Introduction', René Descartes: A Discourse on the Method (A new translation by Ian Maclean; Oxford: Oxford University Press, 2006), lvii-lviii.

66 Descartes, CSM, 2: Second Set of Replies (AT VII 153). And in the Sixth Set of Replies, he says: "I have certainly tried to prove by natural reason that the human soul is not corporeal, but I grant that only faith can enable us to know whether it will ascend above." (AT VII 431).

67 See Letter to Mersenne, 29 August 1639 (CSMK, 3: AT II 570), in which he criticises those who mix the natural light of reason with any graceinspired illumination.

68 John Cottingham, 'The Cartesian Legacy', Proceedings of the Aristotelian Society, Suppl. vol. LXVI (1992), 1-21. 
limits to scientific investigation. It is true that the sciences deal with natural phenomena, but it does not follow that everything that is natural must be physical or entirely subject to causal, or law-like explanations. The mind and its essential connection to a conscious subject, the nature of subjectivity, rationality and its norms and canons cannot be rejected or dubbed supernatural just because they are not amenable to a physical investigation, or a purely causal description. Given the seriousness of the objections raised at the core of nonphysicalism, the conclusion must be that it shares the same fate and instability as the thesis of SP and the other varieties of physicalism that it has repudiated.

Our attempt to understand physicalism and non-physicalism has revealed that the array of problems concerning the nature of the mind or consciousness show that the gap with which we are dealing is not merely epistemological, traceable to our current epistemic limitations, ignorance, or lack of imagination. The explanatory gap is of a different order: it is metaphysical.

\section{$\mathbf{X}$}

What are the implications of the instability and untenability of these theses? If metaphysics is an enquiry into or an investigation of the nature of what there is, of what is real, then the very idea of physical reality, of a true physics, future or ideal, cannot be assumed to exhaust the totality of ontological commitments that a true metaphysics would make. Once we disentangle the absolute conception of reality from the scientific conception (including the special sciences), we come to see afresh that whatever the ambitions and aspirations of the latter, it has to limit itself to one aspect of the world since it cannot deal with the entire fabric of the world.

Casting a favourable light on dualism freed from misconceptions might encourage us to redirect our focus and see that some fundamental rethinking is needed and to take the possibility of the metaphysical distinctness of the mind seriously if we wish to generate new ideas in this area of philosophy. If my arguments are cogent, they lead us to admit (drawing on the imagery cited earlier in the paper) that God creates the totality of facts-after all the notion of the world is neither a scientific nor a physical notion exclusively, but a metaphysical one. "The world is the totality of facts", "the world divides 


\section{God, Physicalism, and the Totality of Facts}

into facts". ${ }^{69}$ To say that some facts are subjective is not simply to comment on the epistemic status of the facts, but to comment on the metaphysical status of one's subject-matter: they are facts about subjective reality. The facts are not physical, or subjective, or objective; this is at best a shorthand way of delineating what kinds of fact there are. Some facts are about the physical, some are facts about the mind and its essential relation to a conscious subject, some are facts about the moral, some are facts about the mathematical, and God knows what else. Our discussion leads us to conclude that none of the sets of fact can be said to have primacy, dominance, or determination, either jointly or severally, over any other set of facts without begging the question. We have no cogent reason, therefore, to endorse the thesis that the physical facts plus the non-physical laws determine the mental facts, any more than we have any cogent reason for endorsing a form of immaterialism. ${ }^{70}$

Progress on the problem of consciousness in general seems, for some time now, to have reached a stalemate among the different varieties of physicalism and non-physicalism with their respective proponents unyieldingly insisting on our epistemic and conceptual limitations, embroiled in and resorting to the production of ever more impressively sophisticated technicalities (however necessary these might be in dealing with some of the issues). There is no doubt that physicalism captured the imagination of some of the leading philosophical minds in the twentieth century, continues to do so, and it has had a deep influence. But with hindsight, when the prevailing paradigm of physicalism wanes and shifts, we shall see that its significance was mainly due to the lessons we can draw from its ultimate indefensibility and untenability. Physicalism in any of its varieties has offered and can offer no promise and no argument that consciousness will cease to be a subjective phenomenon-that per impossibile it will cease to be essentially connected to a conscious subject. In light of the instability and untenability of physicalism on the one hand, and a rejection of immaterialism on the other, it would not be premature to think that we are left with the only possible way forward in our metaphysical explorations that can shed much-needed light on and enable us to begin to understand the truth of both physical

Ludwig Wittgenstein, Tractatus Logico-Philosophicus, David F. Pears $\&$ Brian F. McGuinness (transls.) (Routledge \& Kegan Paul, 1974), §1.1 and $\$ 1.2$.

A defence of this rejection is outside the scope of this paper. 


\section{Andrea Christofidou}

and mental reality: to retrace our steps and start afresh from a clear recognition of the mind and its essential connection to a conscious subject, an embodied self-conscious, autonomous human being-a clear recognition of the mind's place in the world as a metaphysically distinct entity. ${ }^{71}$

Worcester College, Oxford

71 As Descartes explains: "mind and body are incomplete substances when they are referred to a human being which together they make up [...] a unity in its own right" though they have nothing incomplete about them qua substances. (CSM, 2: Fourth Set of Replies AT VII 222).

I should like to thank Stephen Blamey and Peter J. King for their comments on previous drafts. Much earlier versions of this material were presented to a series of lectures on the Philosophy of Mind that I gave for the Faculty of Philosophy at the University of Oxford in 1997, and to various seminars and classes that I have given since. I am grateful to those audiences for their comments. 